www.nature.com/pj

\title{
Design and synthesis of well-defined glycopolymers for the control of biological functionalities
}

\author{
Yoshiko Miura
}

This review addresses the design and synthesis of synthetic glycopolymers. Glycopolymers with pendant saccharides exhibit high affinities for proteins owing to their multivalency. Glycopolymers have molecular recognition abilities and amphiphilicity and can be applied as biomaterials and in bioassays. Most synthetic glycopolymers are prepared from polymerizable saccharide derivatives, and the rest are prepared by saccharide addition to a polymer backbone. Because sugar-recognizing proteins have precise structures, the living polymerization of glycopolymers is important in the fabrication of well-defined multiple ligands of saccharides. Glycopolymers with narrow polydispersity are useful for determining the interactions between saccharides and proteins. The living polymerization of glycopolymers provides hybrid materials by the terminal modification of the polymers. The glycopolymers of block polymers, star polymers and polymer brushes have been investigated for use in novel biomaterials. Polymer Journal (2012) 44, 679-689; doi:10.1038/pj.2012.4; published online 14 March 2012

Keywords: glycopolymer; lectin; living polymerization; molecular recognition

\section{INTRODUCTION}

Much attention has been given to saccharides on cell surfaces because of their biological functions. ${ }^{1,2}$ Protein-saccharide interactions have important roles in cell adhesion, cell differentiation and infection by pathogens such as viruses and protein toxins (Table 1). Proteinsaccharide interactions therefore can be applied as biomaterials in tissue engineering, ${ }^{3}$ drug delivery, ${ }^{4,5}$ biosensors $^{6}$ and medicine. ${ }^{7}$ Protein-saccharide interactions are also important in terms of proteome analyses. ${ }^{8}$

It is well known that protein-saccharide interactions are amplified by the saccharide-assembly structure of glyco-clusters. Monomeric saccharide interactions are weak because protein-saccharide interactions feature weak interactions such as hydrogen bonding and chelation with ions and not strong interactions such as hydrophobic and electrostatic interactions. Saccharide-recognizing proteins (lectins) have multiple sugar-binding sites. ${ }^{9}$ Protein-saccharide interactions are related to pathogens such as influenza viruses, HIV viruses, Shiga toxins (from Escherichia coli O-157:H7), and cholera toxins, all of which have densely packed saccharide-recognizing sites. ${ }^{1,2,9-11}$ The lectin most frequently used in research studies is concanavalin A (ConA), which can recognize $\alpha$-Man $/ \alpha$-Glc. ConA has a tetrameric structure, with four sugar-binding domains; ${ }^{9-11}$ the mannose assembly interacts with several sugar domains and therefore interacts strongly with ConA.

Lee and Lee ${ }^{12}$ were the first to report that sugar assemblies (glycoclusters) strongly bind to proteins. Artificial branched saccharides were prepared and used to investigate interactions with lectins and hepatocytes. They found that the interactions between sugars and proteins and/or cells are much affected by the sugar density. They called this multivalent interaction the 'glyco-cluster effect'. Various glyco-clusters have been reported, such as glycopeptides, ${ }^{13}$ glycomodified-cyclodextrins, ${ }^{14}$ and polymers with pendant saccharides. Compared with low-molecular-weight rigid glyco-clusters, polymers with pendant saccharides exhibit large protein-binding abilities.

Polymers with pendant saccharides are called 'glycopolymers'. Glycopolymers usually exhibit strong interactions because of their high multivalency. In addition, glycopolymers have the appropriate physical properties and material workability to engage in strong interactions. Glycopolymers are prepared from natural and synthetic polymers by several methods (Figure 1). ${ }^{15-18}$ Some glycopolymers have been prepared by polymer reactions with natural products, such as polyglutamate ${ }^{19}$ and alginate, ${ }^{20}$ and synthetic polymers, such as polyacrylate. $^{21,22}$ Natural products such as polyglutamic acid and polyalginate have the advantages of biocompatibility and biodegradability, which make them suitable for drug delivery and tissue engineering. Glycopolymers have also been prepared by the polymerization of saccharide derivatives with polymerizable functional groups ${ }^{15}$ such as vinyl and norbornene. ${ }^{23}$ Some groups have reported the syntheses of glycopolymers by two-step reactions: a first reaction consisting of polymerization with reactive functional groups on sidechains and a second reaction in which sugar is added to the polymer. ${ }^{16,24-26}$ 
Chemically polymerized glycopolymers present many advantages as the components of various materials because of the availability of polymer-chemistry techniques; indeed, block copolymers and graft

Table 1 Examples of proteins, cells and pathogens for saccharide recognition

\begin{tabular}{|c|c|c|}
\hline & Target & Saccharide structure \\
\hline \multirow[t]{2}{*}{ Lectin } & Concanavalin A & $\alpha-\operatorname{Man} / \alpha-G \mid c$ \\
\hline & Wheat germ agglutinin & GlcNAc, Neu5Ac \\
\hline \multirow[t]{2}{*}{ Cell } & Hepatocyte & $\beta-G a l / \beta-G a l N A c$ \\
\hline & Macrophage & $\alpha-\operatorname{Man}$ \\
\hline \multirow[t]{4}{*}{ Pathogen } & $\begin{array}{l}\text { Shiga toxin } \\
\text { (from E. coli 0-157etc) }\end{array}$ & Gb3: Gal $\alpha 1-4$ Gal $\beta 1-4 G \mid c C e r$ \\
\hline & Cholera toxin & $\begin{array}{l}\text { GM1: Gal } \beta 1-3 \text { GalNAc } \beta 1-4 \\
\text { (Neu5Ac } \alpha 3 \text { )Gal } \beta 1-4 \text { GlcCer }\end{array}$ \\
\hline & E. coli Type 1 & $\operatorname{Man} \alpha 1-3(\operatorname{Man} \alpha 1-6) \operatorname{Man}$ \\
\hline & Influenza Type A for human & $\begin{array}{l}\text { Neu5Ac } \alpha 2-6 \text { Gal } \beta 1-4(3) \text { GIcNAc } \beta 1, \\
\text { Neu5Ac } \alpha 2-6 \text { Gal } \beta 1-3 \text { GalNAc } \beta 1\end{array}$ \\
\hline
\end{tabular}

polymers of glycopolymers have been reported. ${ }^{27-29}$ Recent advances in synthetic polymer chemistry have encouraged the synthesis of precise and complex glycopolymers. Because proteins are also polymers with precise structures, control over glycopolymer size and sugar density affects their saccharide biofunctionality. Glycopolymer hybrid materials can be used as novel biomaterials. Precisely synthesized glycopolymers therefore have great potential for use as novel biomaterials. In this review, we focus on glycopolymers, particularly those containing synthetic polymers.

\section{GLYCOPOLYMER DESIGN IN TERMS OF MULTIVALENCY}

Monovalent and multivalent ligands differ fundamentally from each other (Figure 2a). ${ }^{12,30,31}$ Recently, it has been noted that multivalent interactions provide a ubiquitous approach to amplifying biological interactions because lectins, antibodies and receptor proteins have multiple binding sites. ${ }^{32-35}$ All of the ligands in a multiple ligand do not always bind to proteins; thus, the cooperativity of multiple ligands is determined by the protein-binding contribution. In monovalent ligands, there is an energy gain from monovalent binding. In multivalent binding, ligand-protein binding is advantageous not only because of the multiple binding but also because of the multiple

a

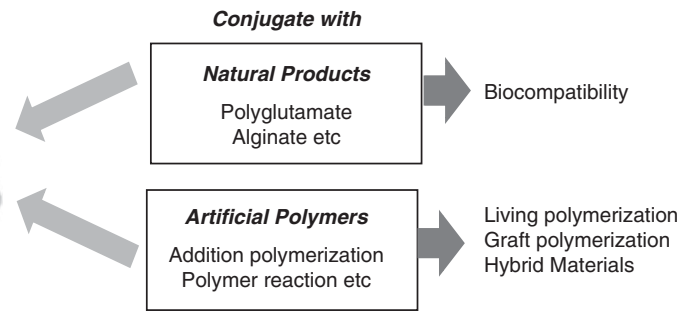

b

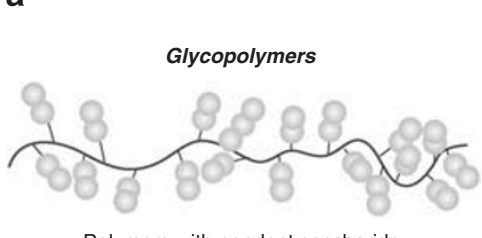

Polymers with pendant saccharide

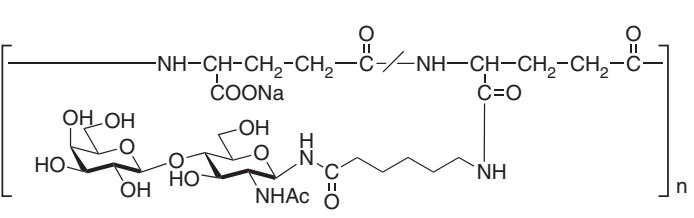

C

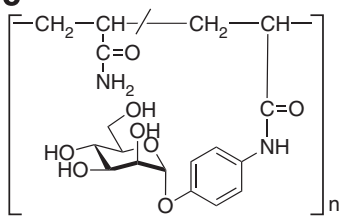

Figure 1 (a) Classification of glycopolymers, (b) representative glycopolymer with a natural product, polyglutamate, and (c) representative glycopolymer with an artificial polymer, polyacrylamide. A full color version of this figure is available at Polymer Journal online.

a

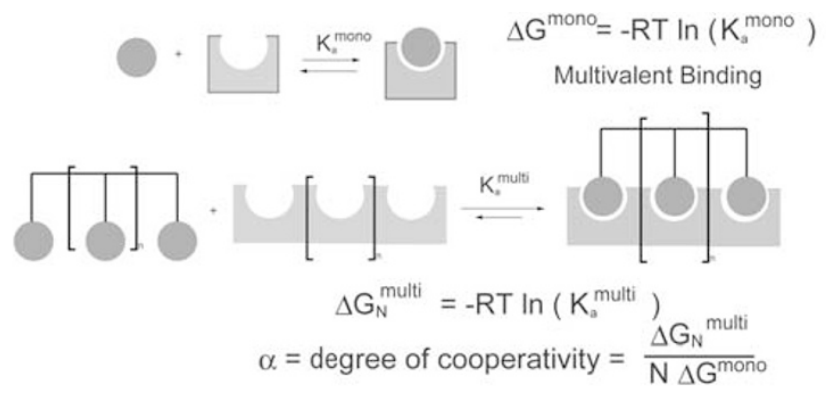

b

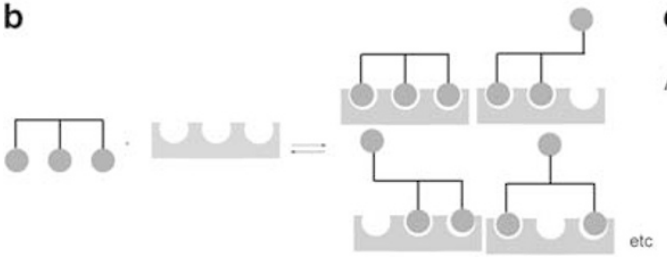

c

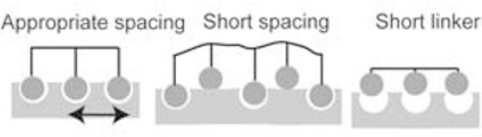

Figure 2 Schematic illustration of sugar binding to lectins: (a) binding of multiple saccharides to proteins, (b) multiple binding of glycopolymers, and (c) glycopolymer binding to proteins with various sugar densities. A full color version of this figure is available at Polymer Journal online. 
binding-modes. ${ }^{36,37}$ For example, multiple ligands provide several binding modes to the same sugar-recognizing sites. Multiple ligands can bind to single binding sites through various binding modes, thereby making them quite diverse (Figure 2b). Glycopolymers provide multiple binding and diverse binding, and these contribute to gains in both enthalpy and entropy. ${ }^{34,38}$

Multiple binding is strongly affected by the structures of the sugarrecognizing sites of lectin (Figure 2c). ${ }^{9-11}$ The distances between the sugar-binding sites and the number of sugar-binding sites are different for each lectin. For example, the distance between the sugar-binding sites in ConA is approximately $8 \mathrm{~nm}$, but that in Shiga-toxin-1 is approximately $1.5-3 \mathrm{~nm} .{ }^{38,39}$ There are four sugar-binding sites in ConA but ten in Shiga-toxin-1. The sugar content of a glycopolymer is related to the saccharide distance; therefore, a glycopolymer with a sugar content that is too dense does not perform as well in recognizing lectin. ${ }^{40,41}$ An appropriate linker structure and polymer mobility are also important. In some cases, glycopolymers with larger molecular weights showed greater molecular-recognition ability as a result of binding to two sugar-recognition sites. ${ }^{42}$ It has been reported that a glycopolymer with a stiff backbone and linker does not bind to lectin ${ }^{43}$ and, conversely, that a glycopolymer of polyrotaxane shows an improved molecular recognition ability as a result of sugar mobility. ${ }^{44}$

\section{EARLY WORK ON GLYCOPOLYMERS, AND THEIR PHYSICOCHEMICAL PROPERTIES}

Synthetic glycopolymers were first reported by Kobayashi et al. ${ }^{45}$ they consisted of polystyrene with a pendant lactose, poly $(N$-vinylbenzyl-O- $\beta$-D-galactopyranosyl-(1-4)-D-gluconamide) (PVLA), or maltose, poly $(N$-vinylbenzyl-O- $\beta$-D-glucopyranosyl-(1-4)-D-gluconamide) (Figure 3). Kobayashi et al. ${ }^{46}$ later reported on the strong binding of PVLA with hepatocytes and Gal-recognition lectins based on the multivalent binding of saccharides. They also reported the application of PVLA in hepatocyte cultures and in drug-delivery systems. In the early days of glycopolymer research, Whiteside et al. ${ }^{21,30,47}$ reported the synthesis of glycopolymers of poly(acrylic acid) derivatives with sialic acid, which showed strong binding to influenza viruses. They also suggested the concept of multivalent binding. Other groups also reported glycopolymer binding to various targets such as bacteria ${ }^{48}$ and RNA. ${ }^{49}$ Early work on glycopolymers showed that glycopolymers had strong molecular-recognition abilities compared with monovalent ligands and multivalent ligands with lowmolecular-weight, rigid structures.

The physicochemical properties of glycopolymers have also been investigated. Glycopolymers essentially have an amphiphilic structure, with a hydrophobic C-C backbone and hydrophilic saccharide side-chains. The self-assembling properties of the amphiphilic glycopolymer PVLA have been investigated. It was found that PVLA selfassembled as micelles, which are adsorbed at hydrophobic interfaces. ${ }^{50}$ A glycopolymer with a styrene backbone was observed to form rodlike structures in solution as a result of the isotacticity of the polymer backbone and the amphiphilicity. ${ }^{51,52}$ Rod-like glycopolymers involve a hydrophobic guest; thus, they can be used in drug-delivery systems with hydrophobic medicinal compounds. We also found that glycopolymers can interact with hydrophobic $\pi$-conjugated polymers to form polymer nanowires by polymer-polymer complexation..$^{53}$ Glycopolymers also adsorb onto hydrophobic interfaces as a result of hydrophobic interactions; this provides a biological interface that can be created by a facile coating process. ${ }^{54,55}$ The adsorption of glycopolymers to interfaces such as hydrophobic polymer interfaces, self-assembled monolayers and micropatterned substrates provide cell-cultivation materials and biosensing interfaces.

\section{GLYCOPOLYMERS VIA LIVING POLYMERIZATIONS}

Synthetic glycopolymers can be precisely prepared by living radical polymerizations (Figure 4). ${ }^{56-60}$ The vinyl derivatives of saccharides can be polymerized by living radical polymerization. Even when the monomer structure of the glycopolymer is bulky with high steric hindrance, recent advances in polymer chemistry have enabled the living radical polymerization of glycopolymers via various techniques such as nitroxide-mediated radical polymerization, ${ }^{61}$ atom-transfer radical polymerization (ATRP), ${ }^{62,63}$ and reversible addition-fragment chain transfer (RAFT) polymerization. ${ }^{64}$

Ohno et al.65,66 first reported the living radical polymerization of a glycopolymer using nitroxide-mediated polymerization. They polymerized $N$-vinyl-benzyl-O- $\beta$-D-galactopyranosyl-(1-4)-D-gluconamide (VLA) and acetylated VLA (AcVLA). The living radical polymerization was successfully accomplished using di-tert-butyl nitroxide in DMF, and the protected glycopolymers showed higher conversions compared with conversion using 2,2,6,6-tetramethylpiperidine 1-oxyl (TEMPO). The nitroxide-mediated living radical polymerization of glycopolymers showed a time-dependent increase in molecular weight. The researchers were able to produce glycopolymers with defined molecular weights, which enabled the analysis of glycopolymer conformations. ${ }^{67}$ Other groups also reported nitroxidemediated living radical polymerizations. ${ }^{68-72}$ Most of the monomers that have been used are styrene derivatives of saccharides with protected groups. For example, Kakuchi et al. ${ }^{70-73}$ reported the TEMPO-mediated living radical polymerization of glycopolymers of

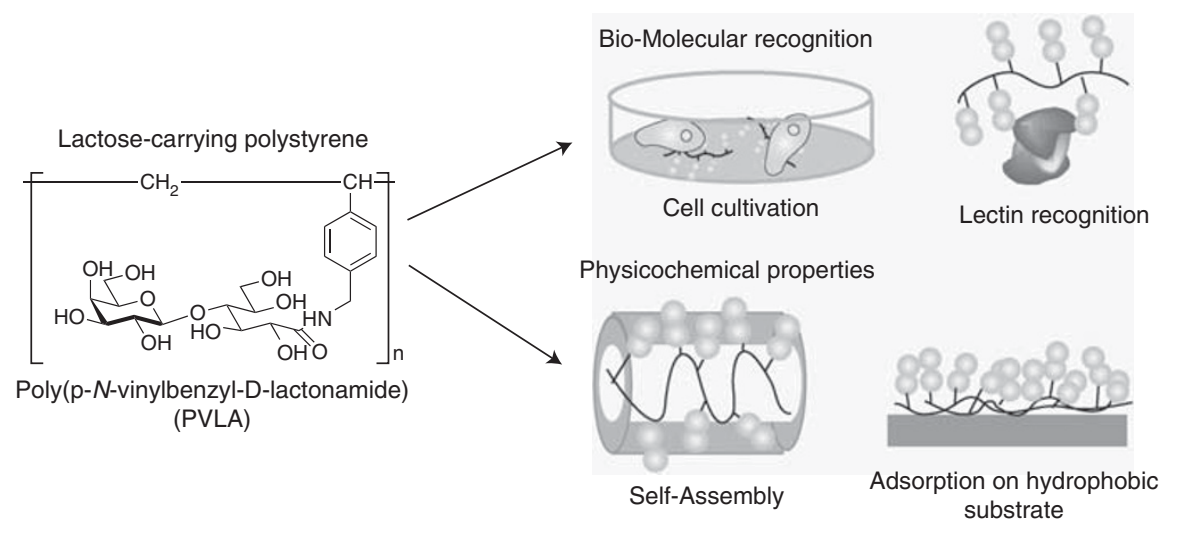

Figure 3 Chemical structure and properties of lactose-carrying polystyrene. A full color version of this figure is available at Polymer Journal online. 
<smiles>[R]NCCCOC(=O)C(=C)C</smiles>

$\mathrm{R}_{1}=$

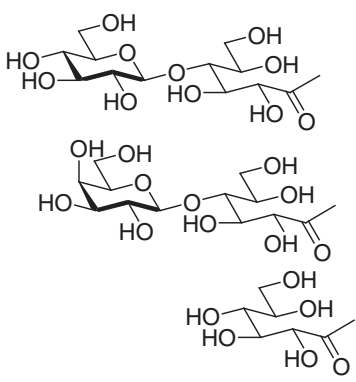

b

Ring-opening metathesis polymerization
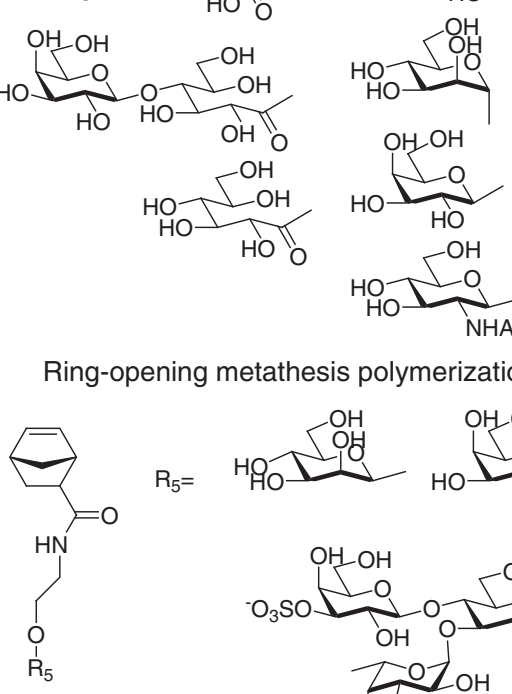<smiles>[R]OCCOC(=O)C(=C)C</smiles>

$\mathrm{R}_{2}=$
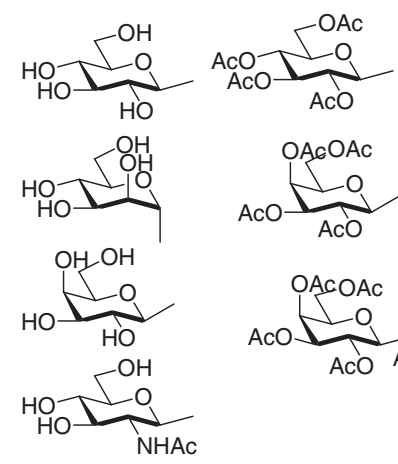

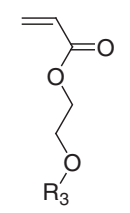

$\mathrm{R}_{3}=$
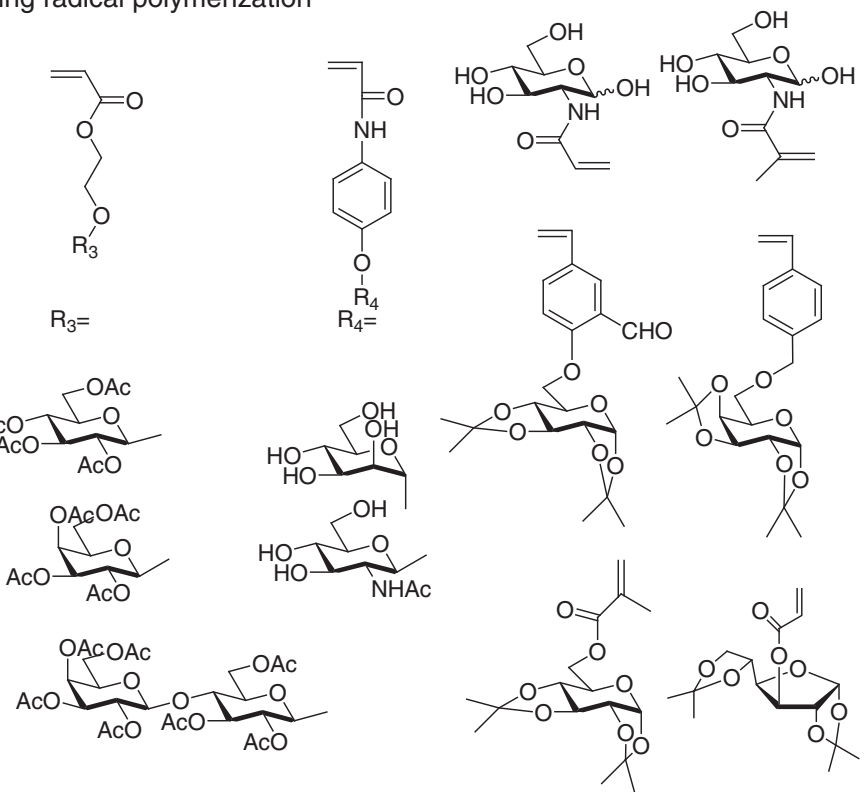

C Polymerization and saccharide addition
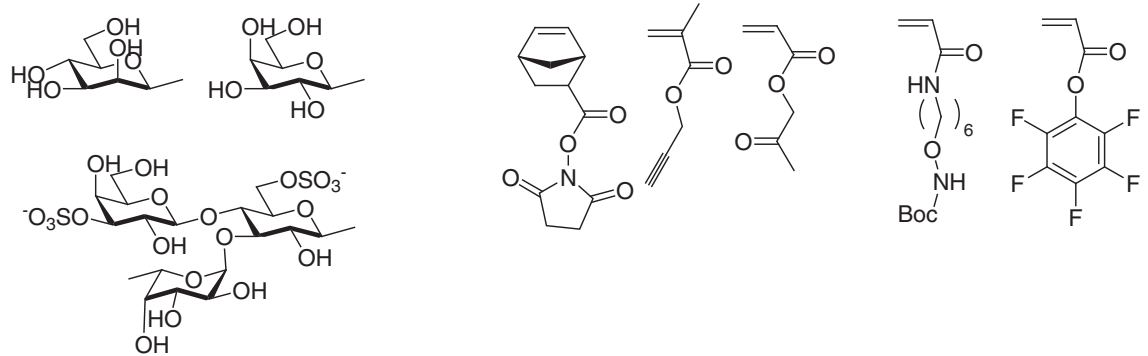

Figure 4 Monomer structures of glycopolymers used for living polymerization: monomers for (a) living radical polymerization, (b) ring-opening olefin metathesis, and (c) polymerization with the saccharide-reactive group.

4-vinylbenzyl pentaacetate glucose. They synthesized homopolymers and block copolymers with polystyrene. Star-shaped block copolymers of polystyrene and glycopolymers were also synthesized with a divinyl benzoate cross-linker.

ATRP is another notable method used for living radical polymerization, in which a metal complex at the polymer-chain terminal mediates the controlled polymerization. ATRP is affected by the type of ligand, the metal, the initiator and the solvent. Ohno et al. ${ }^{73}$ also first reported the living radical polymerization of 3-O-methacryloyl1,2,5,6-di-O-isoproylidine-D-glucoside with an alkyl halide/copper complex system. The homopolymer and block copolymer with polystyrene were synthesized by ATRP in high yields. Narain and Armes ${ }^{27,74}$ reported living radical polymerization by ATRP using two unprotected monomers of 2-gluconamidoethyl methacrylate and 2-lactobionamidoethyl methacrylate. Narain and Armes synthesized glycopolymers with $\mathrm{CuBr}$ and 2,2-bipyridine with a macroinitiator of poly(ethylene oxide), poly(propylene oxide) or poly ( $\varepsilon$-caprolactone) in methanol and aqueous solutions. The synthesis was dependent on the solvent system, and the glycopolymers were obtained in high yields in aqueous solutions. They also synthesized block copolymers with methacrylate derivatives. Other groups also reported the living radical polymerization of glycopolymers and synthesized various glycopolymers, including block copolymers, ${ }^{27,74,75}$ hyperbranched polymers ${ }^{76}$ and star polymers. ${ }^{77,78}$ The advantage of ATRP is the versatility of the initiator design, which enables the synthesis of various types of polymers. The immobilization of the initiator on a substrate enables the formation of densely packed polymer brushes, ${ }^{79-81}$ and special bioconjugate initiators have also been reported. Glycopolymer brushes synthesized by ATRP engage in specific interactions with proteins and cells; this is discussed in a later section.

RAFT is another living radical polymerization method. RAFT polymerization involves the addition of a thiocarbonyl RAFT reagent. McCormick et al. ${ }^{82}$ first synthesized glycopolymers of 2-methacryloxyethyl glucoside with RAFT reagents. RAFT affords the living radical polymerization of various monomers such as styrene, ${ }^{83,84}$ methacrylate, ${ }^{85-90}$ acrylamide, ${ }^{91}$ acylate ${ }^{92}$ and vinyl acetate ${ }^{93}$ derivatives of saccharides. More diverse monomers can be synthesized through RAFT than through ATRP or nitroxide-mediated living radical polymerization. For example, the vinyl ester derivative of the glycomonomer 6-vinyladipoylD-glucopyranoside was successfully polymerized with the RAFT reagent 4-cyano-4-diethylthiocarbamoylsulfanyl-4-methylbutyric acid. ${ }^{93,94}$ Another advantage of RAFT polymerization is the use of polymer terminals, ${ }^{95}$ where terminal dithioesters and trithioesters are easily converted into thiol groups. The reactive functional thiol end is available for $\mathrm{Au}-\mathrm{S}$ bond formation; ${ }^{96}$ Michael addition with maleimide and thiol-ene reactions ${ }^{97,98}$ provide versatile hybrid glycopolymer materials. 
Recently, glycopolymer synthesis via living radical polymerization and a subsequent polymer reaction was reported. The polymerization of a glycomonomer is more difficult than that of a simple monomer because of the steric hindrance of the side-chain, and glycopolymer yields are usually low. One solution to the difficulty of such polymerizations is a sophisticated living radical polymerization. Another solution is the polymerization of a functional monomer with a reactive side-chain that is smaller than a saccharide. Haddleton et al. ${ }^{15}$ prepared and polymerized acetylene-substituted methacrylate, and the obtained polymer was modified with saccharides containing azide groups by click chemistry. Bertozzi et al. ${ }^{26}$ prepared and polymerized a ketone-substituted methacrylate, and the obtained polymer was conjugated with aminooxy saccharides. Kaminati et al. ${ }^{99}$ reported the synthesis of polymer brushes of a polyacylate with aminooxy side-chains, and the obtained polymer brush was reacted with the reductive terminal of a saccharide. Boyer et al. ${ }^{97}$ reported that an activated ester of acrylic acid can be polymerized by living polymerization; in their work, a saccharide with an amine was modified by amide-bond formation. You et al. ${ }^{100}$ reported the polymerization of butadiene and glycopolymer preparation by a thiolene reaction with 1,2,3,4,6-tetra- $O$-acetyl- $\alpha$-D-1-thioglucopyranose. A combination of living radical polymerization and a polymer reaction is a facile method of preparing fine-tuned glycopolymers. Ring-opening olefin metathesis polymerization (ROMP) with succinimide and sugar addition also provides fine-tuned glycopolymers. ${ }^{101}$

ROMP provides fine-tuned glycopolymers ${ }^{102}$ and is advantageous in the synthesis of fine-tuned glycopolymer because it is tolerant of bulky side-chains and harsh solvents. ROMP also provides glycopolymers with narrow polydispersity in a living manner. Kiessling et al. ${ }^{103,104}$ reported the synthesis of various glycopolymers by ROMP. The glycopolymers synthesized by ROMP provided synthetic glyco-clusters with fine-tuned densities and molecular weights. They reported that differences in the molecular weight, polymer backbone, and polydispersity of the glycopolymers affected the polymers' specific binding to lectin. ${ }^{103}$ Polymer binding to lectin was affected not only by multivalency and cooperativity but also by the kinetics and mobility of the glycopolymer.

The advantage of living polymerization is that it provides precise glycopolymer characteristics such as molecular weights with narrow polydispersities and random saccharide spacing (Figure 5). As shown in Figure 2, the biological abilities of glycopolymers depend on lectin properties such as the structures of the sugar-binding sites, the

\section{a Free radical polymerization}

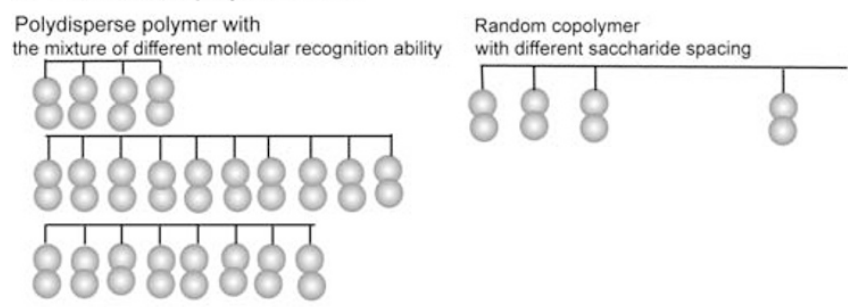

b

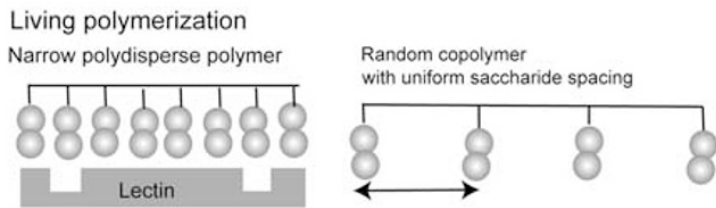

Figure 5 Properties of glycopolymers synthesized via (a) free-radical polymerization and (b) living polymerization. distances between sugar-binding sites, and the receptor distribution in the cell membrane. The living polymerization of glycopolymers allows for the analysis of saccharide-protein interactions and control of biological functions based on the use of precise structures. In the case of free-radical polymerization, it is difficult to obtain glycopolymers with narrow polydispersity and uniform saccharide spacing and therefore difficult to determine the detailed interactions that occur between proteins and saccharides, although glycopolymers obtained via free-radical polymerization show strong molecular recognition. The living polymerization of glycopolymers can reveal the structures of sugar-binding sites, the distances between sugar-binding sites, and their distribution. Thus, living polymerization is useful for the proteomic analysis of proteins with unknown structure and functions. Kiessling et al., Haddleton et al., and we have investigated lectin binding with fine-tuned glycopolymers obtained via living polymerization. Kiessling et al. ${ }^{105}$ synthesized glycopolymers containing mannose of various molecular lengths (molecular weight) and sugar densities by ROMP and investigated ConA binding (Figure 6). Glycopolymers with different degrees of polymerization (DPs) showed different binding affinities. Polymers with DPs over 50 showed affinities that were over 100-fold stronger than those with DPs of 7. The DP decides the molecular length of a polymer, and longer polymers show stronger affinities as a result of bivalent binding. Glycopolymers with different sugar densities were also synthesized; glycopolymers with higher sugar densities showed better affinities, although too high a sugar density is unfavorable because it causes negative multivalent effects. ${ }^{103}$ Haddleton et al. ${ }^{15,106}$ synthesized glycopolymers by living radical polymerization and click chemistry. They connected two types of saccharides of mannose and galactose to change the density of one sugar. The binding affinity of a glycopolymer to ConA depends on the corresponding saccharide density of mannose. We synthesized PVLA by nitroxide-mediated living radical polymerization. We synthesized glycopolymers with various molecular weights, and glycopolymers with larger DPs showed better binding to $\mathrm{RCA}_{120}$ lectin. ${ }^{42}$ In the cases of ConA and $\mathrm{RCA}_{120}$, the distances between sugar-binding sites were approximately $6-10 \mathrm{~nm}$; thus, a glycopolymer with a sufficient DP can show strong bivalent binding.

a

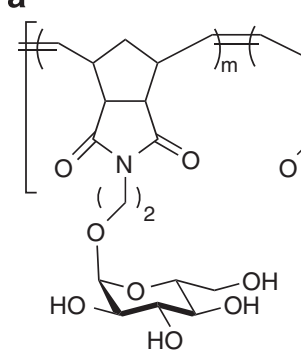

b

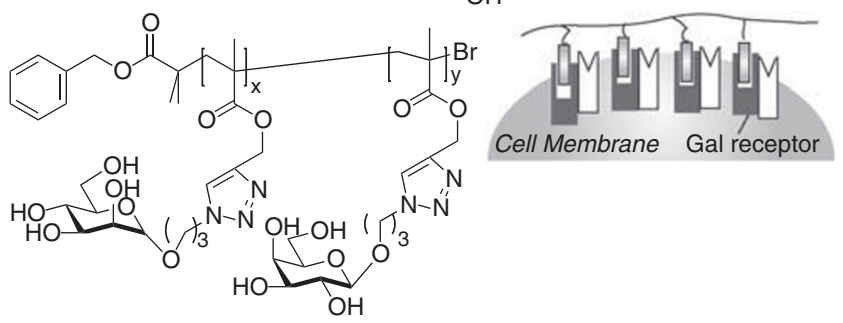

Figure 6 Glycopolymers via living polymerization for biological applications: (a) control of multivalent effect with changing saccharide density and (b) clustering of receptor proteins with a glycopolymer carrying Gal on cell surfaces. 
These examples suggest that glycopolymers synthesized by living radical polymerization control sugar clusters and regulate their own molecular-recognition ability.

Kiessling et al. ${ }^{107}$ also reported the molecular-recognition abilities of glycopolymers with various polymer backbones using ConA. They synthesized various glycopolymers with polynorbornene, poly(ethylene-maleic anhydride), and polyamidoamine dendrimeric backbones, and other multivalent glyco-clusters of globular proteinconjugates and small synthetic multivalent ligands. It was observed that the molecular-recognition abilities of glycopolymers and other multivalent ligands depended on the shape, size, and density of saccharides because saccharide-protein-recognition events are related to various binding modes, including multivalent binding to lectin and lectin clustering. The results indicated that multivalent interactions and molecular dynamics, based on the backbone structure, are both important in molecular recognition.

Kiessling et al. also reported glycopolymers that interact with receptors on cell surfaces and suggested the potential application of these glycopolymers for controlling cell functions using multivalent interactions (Figure 6). Kiessling et al. investigated the communication of receptor proteins on cell surfaces using glycopolymers and also reported the interaction of a Gal-carrying glycopolymer with E. coli, in which the glycopolymer interacts with receptors on the cell surfaces. The Gal-recognition receptor showed clustering caused by the interactions of the glycopolymer, which changed the migration properties. The glycopolymer also induced the clustering of other receptors due to interactions with Gal receptors and inter-receptor communication. ${ }^{104}$ The researchers also examined an end-functionalized glycopolymer to monitor the cell behavior, where the glycopolymer terminal was conjugated and fluorescent. ${ }^{108}$ Glycopolymers carrying sulfonated saccharides showed affinities for L-selectin and T-cells (Jurkat cells).

Glycopolymers with precise structures showed specific interactions with disease proteins. The binding properties suggest the biofunctionality of the disease proteins. We found that protein binding depends on the molecular weight and sugar density ${ }^{42}$ and reported glycopo- lymers carrying sulfonated GlcNAc produced by RAFT living radical polymerization, which interact with Alzheimer's amyloid $\beta$-protein $(A \beta)$ to inhibit protein aggregation. ${ }^{109,110}$ The interaction with $A \beta$ was dependent on the molecular weight and sugar density, and lowmolecular-weight glycopolymers showed better inhibitory effects. Haddleton et al. ${ }^{11}$ reported detailed interactions with lectins. Glycopolymers containing $\alpha$-Man showed an affinity for DC-SIGN of the mannose-recognizing protein and inhibited interactions with glycoprotein gp120 from the HIV virus. The interactions with DC-SIGN varied with the sugar ratio, and a high Man ratio in the polymer produced a better affinity for DC-SIGN.

Glycopolymers prepared precisely via living polymerization provided fine-tuned saccharide spacing and glyco-cluster size; these revealed the functionality of the saccharide. Understanding the interactions between receptor proteins and other membrane proteins are the key to understanding biological signals. Using artificial glycopolymer ligands, the influence of saccharide clusters on the protein receptor and other receptors was easily investigated using fine-tuned glyco-clusters. The density and polymer molecular weight directly influenced cell avidity, protein recognition, pathogen binding, and receptor communication.

\section{SYNTHESIS OF FUNCTIONAL GLYCO-MATERIALS VIA LIVING POLYMERIZATION}

The living polymerization of glycopolymers is advantageous in preparing various complex polymers and hybrid materials (Figure 7), that is, the living polymerization of glycopolymers enables the synthesis of polymers with complex structures. Living polymerization can promote conjugation with other materials such as grafted substances, ${ }^{77,112,113}$ nanocarbones, ${ }^{114,115}$ and nanoparticles. ${ }^{116}$ The conjugation of glycopolymers with other materials provides additional functionalities. Glycopolymer conjugation with gold nanoparticles, ${ }^{117}$ quantum dots ${ }^{118}$ and fluorophores ${ }^{106}$ provide photochemical properties, which can be used in bioassays, and conjugation with gold and silicon substrates provides electrochemical properties, which can be used in biosensors and other devices. Block copolymers and star a

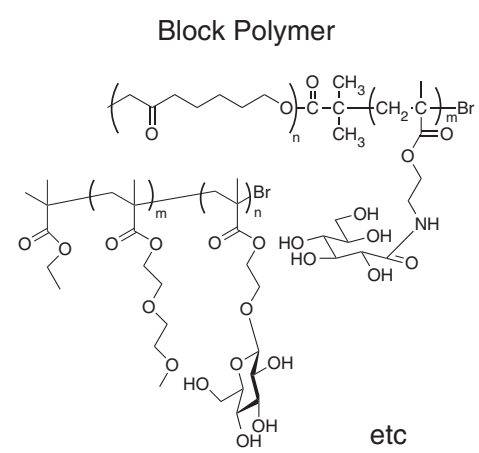

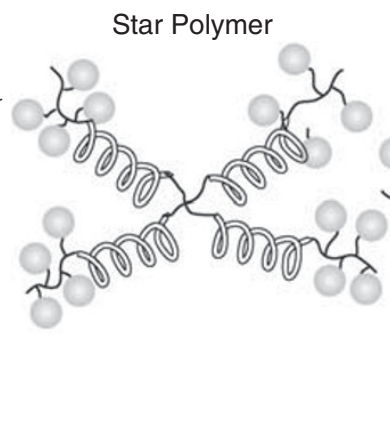

Nanocarbon Conjugate

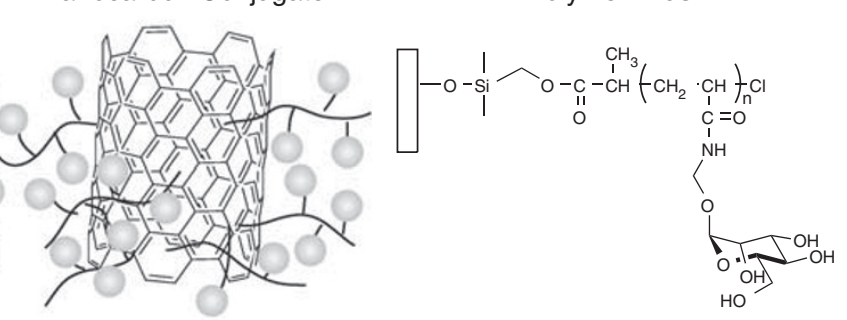

b

RAFT

Au-S Bond Formation
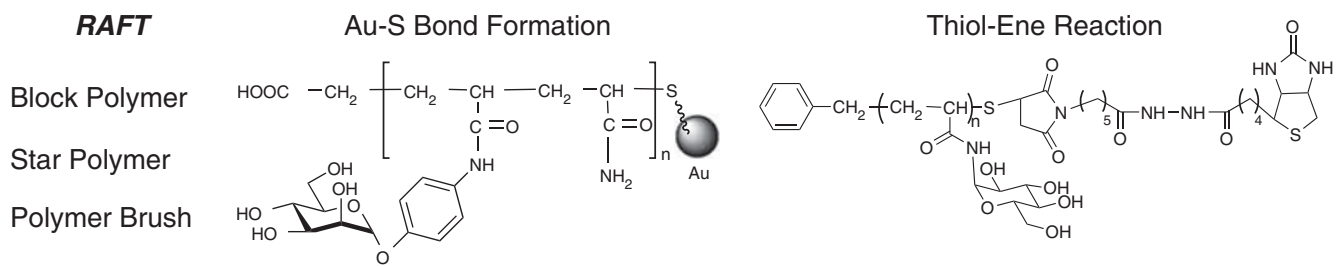

Figure 7 Representative glyco-materials synthesized via (a) ATRP and (b) RAFT. A full color version of this figure is available at Polymer Journal online. 
polymers with hydrophobic cores form nanoparticles that can encapsulate hydrophobic compounds.

Block copolymers have been synthesized by living radical polymerization. Narain and Armes ${ }^{27,74}$ reported the synthesis of biocompatible block copolymers by ATRP using glycopolymers and poly(ethylene oxide). Glycopolymers with hydrophobic segments such as polystyrene, ${ }^{70,72}$ PMMA, ${ }^{117}$ and biodegradable polyesters ${ }^{77,119,120}$ formed amphiphilic molecules that form micelles and particles. A star initiator was used for the synthesis of various glycopolymers, and star glycopolymers with poly( $\varepsilon$-caprolactone) were produced for the synthesis of biodegradable glycopolymers, which could be applied to deliver the drug doxorubicin. ${ }^{77,119,120}$ A block glyco-copolymer with oligo(polyethylene glycol), synthesized by ATRP and RAFT polymerization, showed stimuli-responsive properties. ${ }^{85}$

We have reported the living radical polymerization of glycopolymers by the RAFT method (Figure 8) using p-acrylamidophenyl $\alpha$-Man and $\beta$-GlcNAc, in which the molecular terminals of the glycopolymers were reduced to thiol groups. ${ }^{121,122}$ The thiol-terminated glycopolymers easily modified gold nanoparticles and gold substrates via $\mathrm{Au}-\mathrm{S}$ bond formation. The glycopolymer-modified gold nanoparticles exhibited biological recognition in reacting to proteins and bacteria. The gold nanoparticles showed a sensitive color change as a result of the aggregation of nanoparticles via protein-saccharide interactions; this color change was observed to be protein-specific. Thiol-terminated glycopolymers can modify gold substrates to provide biointerfaces, and the glycopolymer-modified gold substrates can form a polymer membrane with a pancake-like structure, which shows strong lectin affinity. The obtained gold nanoparticles and substrates are used as biosensors in lateral-flow assays and electrochemistry. ${ }^{123,124}$ The glycopolymer-modified substances showed large bioaffinities as a result of their multivalency, and they exhibited high specificities because the glycopolymer is bioinert, except toward lectin because of its high hydrophilicity.

Narain et al. ${ }^{27,74,86,114,116}$ reported various glycopolymers using ATRP and RAFT polymerization. They synthesized glyco-nanoparticles of 2-gluconamidoethyl methacrylate and 2-lactobionamidoethyl methacrylate to achieve biocompatibility. They synthesized block copolymers with cationic 3-aminopropyl methacrylamide monomers, and the polymer showed permeability to and biocompatibility with human cell lines. ${ }^{125,126}$ Glyco-nanoparticles with cationic segments and biotin were observed to be efficient transfection carriers. Glycopolymer-modified gold nanoparticles were also synthesized using RAFT terminals to prepare glycopolymer-substituted gold nanoparticles with biorecognition abilities and biocompatibilities.

The bioconjugation of glycopolymers was investigated by living polymerization. Maynard et al. ${ }^{127}$ synthesized bioconjugated glycopolymers using biofunctionalized initiators. They synthesized a peptide initiator in which the Ser residue was modified as the initiator and polymerized a glycopolymer carrying GlcNAc. They also synthesized glycopolymers using a biotin derivative as an initiator and synthesized biopolymer conjugates of RNA and proteins using disulfide-exchange reactions. ${ }^{128}$ Gupta et al. ${ }^{129}$ synthesized glycopolymer conjugates with viral surfaces. The capsid protein of the virus was modified with an azide and connected with a glycopolymer by click chemistry. The obtained polymer was labeled with a fluorophore, and the modified virus was visualized using fluorescence.

Whittaker et al. ${ }^{130}$ reported a novel route for synthesizing hyperbranched glycopolymers via RAFT living radical polymerization and

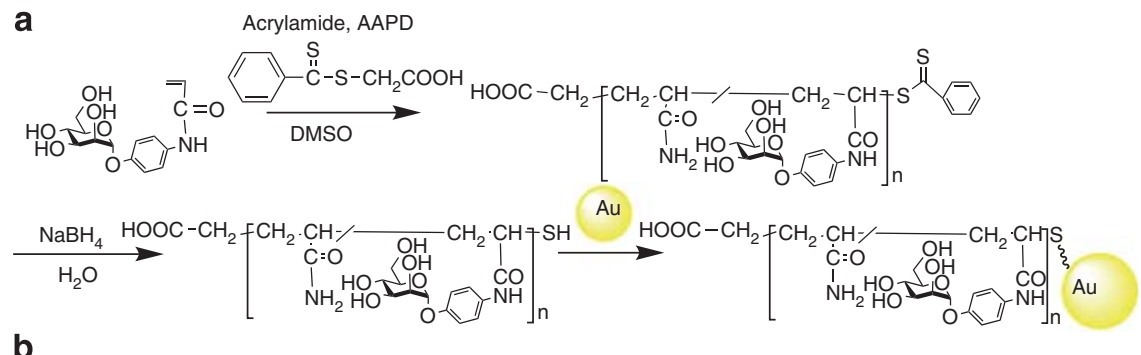

b
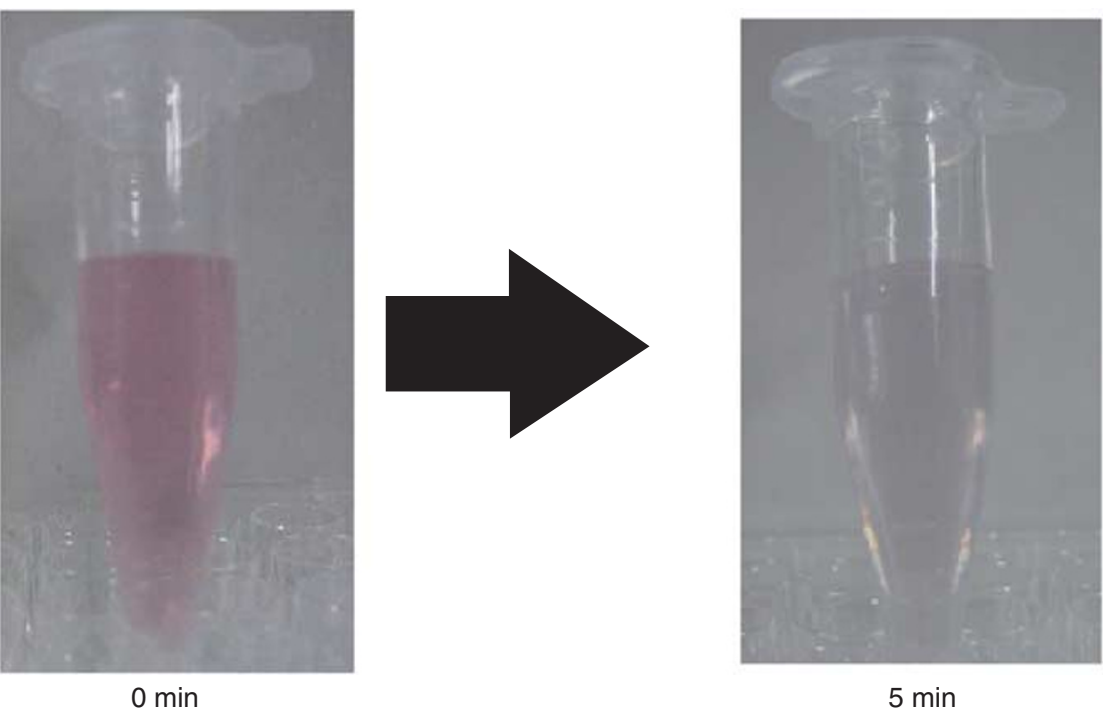

$5 \min$

Figure 8 (a) Glycopolymer-modified gold nanoparticles synthesized via reversible addition-fragment chain-transfer living radical polymerization and applications to biosensing; (b) colorimetric changes of gold nanoparticle with glycopolymer by the addition of $1 \mu \mathrm{m}$ ConA. 
click chemistry. These researchers synthesized copolymers of dimethylaminoethyl acrylate, trifluoroethyl acrylate and ethyleneglycol dimethacrylate, incorporating an alkyne terminal. The obtained polymer terminal was modified with $\alpha$-mannose via click chemistry. The obtained hyperbranched polymer showed a specific affinity for kidney cells, and kidney cells were visualized by F-19 magnetic resonance imaging using the hyperbranched glycopolymer.

Using a modified initiator or immobilized initiator, various glycopolymer brushes were prepared on various materials. Using a hydrophobic initiator, a glycopolymer was synthesized to modify carbon nanotubes, and the carbon nanotubes were solubilized by the glycopolymer brushes. ${ }^{115,116}$ Bertozzi et al. ${ }^{131}$ prepared glycopolymer-modified nanotubes using a C18-tailed initiator and were able to modify the carbon nanotubes based on amphiphilicity. The polymer-modified nanotubes were soluble in aqueous solutions, and the modified carbon nanotubes showed efficient incorporation of nanotubes into cells as a result of the molecular-recognition abilities of saccharides.

The glycopolymer brushes were prepared on the interface by a grafting-from method, in which more densely packed brushes were formed than in the grafting-to method. ${ }^{132}$ The modification of substances with polymer brushes imparts biological recognition abilities to lectins, cells, and bacteria. Glycopolymer brushes have been fabricated on various substrates, ${ }^{99}$ such as flat substrates, porous substrates, and particles by the immobilization of an initiator. $^{112,133-136}$ Glycopolymer brushes exhibit biological recognition abilities, and the molecular-recognition abilities of the brushes are amplified by the glyco-cluster effect. ${ }^{134,136}$ The brushes also show bioinert surface properties, which assist the fabrication of biomaterials designed to induce specific interactions; ${ }^{135}$ for example, a peptide was immobilized with a glycopolymer brush, which showed specific biological recognition. ${ }^{136}$ Molecular-recognition abilities and bioinert properties are affected by density and layer thickness; these can be precisely controlled by a surface-initiated living polymerization method. The incorporation of glycopolymers onto these substrates has been observed to induce specific recognition abilities and will be used in various biological devices such as cell-cultivation systems, diagnostic devices and affinity-purification membranes in the near future. The fabrication and detailed analyses of the substrates are still being examined by many groups worldwide.

\section{CONCLUSION}

Glycopolymers are interesting materials as models of glycoproteins, glycolipids, and polysaccharides. On the basis of multivalent proteinsaccharide interactions, it is possible to synthesize materials with affinities for proteins, cells, and pathogens. The polymer components of glycopolymers are also important because they can be controlled by polymer chemistry, unlike those of other artificial glyco-clusters. The living polymerization of glycopolymers allows for the fine-tuning of saccharide distances and molecular weights. These precisely structured glycopolymers are useful in identifying saccharide functions for the analyses of receptor proteins on cell surfaces and glyco-cluster effects in living systems. In addition, living polymerization is useful in synthesizing polymers with special structures, such as block and star polymers, and hybrid polymer materials, such as bioconjugates and polymer brushes. Block and star polymers of glycopolymers exhibit molecular-recognition abilities, biocompatibility and biodegradability. Hybrid materials with other substances show hydrophilicity, molecular recognition abilities, and biocompatibility. Glycopolymers combined with other substances can be used to synthesize biofunctional materials for applications in tissue engineering, drug-delivery systems, and biosensing. I believe that living polymerization provides a practical route for synthesizing glycopolymers with novel structures that exhibit useful functions as biomaterials.

\section{ACKNOWLEDGEMENTS}

I am grateful for the financial support provided by the Grant-in-Aid for Scientific Research on Innovative Areas 'Soft Interfaces' (20106003). I am also grateful to emeritus Prof. Kazukiyo Kobayashi (Nagoya University) for the helpful discussions we shared.

1 Dwek, R. A. Glycobiology: toward understanding the function of sugars. Chem. Rev. 96, 683-720 (1996).

2 Taylor, M. E. \& Drickamaer, K. Introduction to Glycobiology (Oxford Press, London, 2002).

3 Cho, C. S., Seo, S. J., Park, I. K., Kim, S. H., Kim, T. H., Hoshiba, T., Harada, I. \& Akaike, T. Galactose-carrying polymers as extracellular matrices for liver tissue engineering. Biomaterials 27, 576-585 (2006).

4 Costantino, L., Gandolfi, F., Bossy-Nobs, L., Tosi, G., Gurny, R., Rivasi, F., Vandelli, M. A. \& Forni, F. Nanoparticulare drug carries based on hybrid poly(D,L-lactide-co-glycolide)-dendron structures. Biomaterials 27, 4635-4645 (2006).

5 Ahmes, M. \& Narain, R. The effect of polymer architechture, composition and molecular weight on the properties of glycopolymer-based non-viral gene delivery systems. Biomaterials 32, 5276-5290 (2011).

6 Jelinek, R. \& Kolusheva, S. Carbohydrate biosensors. Chem. Rev. 104, 5987-6016 (2004)

7 Gruner, S. A., Locardi, E., Lohof, E. \& Horst, K. Carbohydrate-based mimetics in drug design: sugar amino acids and carbohydrate scaffolds. Chem. Rev. 102, 491-514 (2002)

8 Blix, O., Head, S., Mondala, T., Scanian, C., Huflejt, M. E., Alvarez, R., Bryan, M. C., Fazio, F., Calarese, D., Stevents, J., Razi, N., Stevens, D. J., Skehel, J. J., van Die, I., Burton, D. R., Wilson, I. A., Cummings, R., Bovin, N. \& Wong, C.- H. Printed covalent glycan array for ligand profiling of diverse glycan bidning proteins. Proc. Natl Acad. Sci. USA 101, 17033-17038 (2004).

9 Rini, J. M. Lectin structure. Annu. Rev. Biophys. Biomol. Struct. 24, 551-577 (1995).

10 Lis, H. \& Sharon, N. Lectins: carbohydrate-specific proteins that mediate cellular recognition. Chem. Rev. 98, 637-674 (1998).

11 Nilsson, C. L. Lectins: Analytical Technologies (Elsevier, The Netherlands, 2007).

12 Lee, T. C. \& Lee, R. T. Carbohydrate-protein interactions: basis of glycobiology. Acc. Chem. Res. 28, 321-327 (1995).

13 Grigalevicius, S., Chierici, S., Renaudet, O., Lo-Man, R., Dériaud, E., Leclerc, C. \& Dumy, P. Chemoselective assembly and immunological evaluation of multiepitopic glycoconjugates bearing clusterd Tn antigen as synthetic anticancer vaccines. Bioconjug. Chem. 16, 1149-1159 (2005).

14 Baussanne, I., Benito, J. M., Ortiz Mellet, C., García Fernández, J. M. \& Defaye, J. Dependence of concanavalin A binding on anomeric configuration, linkage type, and ligand multiplicity for thiourea-bridged mannopyranosyl- $\beta$-cyclodextrin conjugates. ChemBioChem. 2, 777-783 (2001).

15 Slavin, S., Burns, J., Haddleton, D. M. \& Bercer, C. R. Synthesis of glycopolymers via click reactions. Eur. Polym. J. 47, 435-446 (2011).

16 van Dongen, S. F., de Hoog, H. P., Peters, R. J., Nallani, M ., Nolte, R. J. \& van Hest, J. C. Biohybrid polymer capsules. Chem. Rev. 109, 6212-6274 (2009).

17 Jayaraman, N. Multivalent ligand presentation as a central concept to study intricate carbohydrate-protein interactions. Chem. Soc. Rev. 38, 3463-3483 (2009).

18 Miura, Y. Synthesis and biological application of glycopolymers. J. Polym. Sci. Part A: Polym. Chem. 45, 5031-5036 (2007).

19 Ogata, M., Hidari, K. I., Kozaki, W., Murata, T., HIratake, J., Park, E. Y., Suzuki, T. \& Usui, T. Molecular design of spacer-N-linked sialoglycopolypeptide as polymeric inhibitors against influenza virus infection. Biomacromolecules 10, 1894-1903 (2009).

20 Kaneko, Y. \& Kadokawa, J.- I. Synthesis of nanostructured bio-related materials by hybridization of synthetic polymers with polysaccharides or saccharide residues. J. Biomater Sic. Polym. Ed. 17, 1269-1284 (2006).

21 Choi, S.- K., Mammen, M. \& Whitesides, G. M. Generation and in situ evaluation of libraries of poly(acrylic acid) presenting sialosides as side chains as polyvalent inhibitors of influenza-meidated hemagglutination. J. Am. Chem. Soc. 119, 4103-4111 (1997).

22 Wu, W.- Y., Jin, B., Krippner, G. Y. \& Watson, K. G. Synthesis of a polymeric 4-N-linked sialoside which inhibits influenza virus hemagglutinin. Bioorg. Med. Chem. Lett. 10, 341-343 (2000).

23 Fraser, C. \& Grubbs, R. H. Synthesis of glycopolymers of controlled molecular weight by ring-opening metathesis polymerization using well-defined functional group tolerant ruthenium carbine catalystst. Macromolecules 28, 7248-7255 (1995).

24 Miura, Y., Kato, K., Takegawa, Y., Kurogchi, M., Furukawa, J.- I., Shinohara, Y., Nagahori, N., Amano, M., Hinou, H. \& Nishimura, S.- I. Glycoblotting-assisted O-glycomics: ammonium carbamate allows for highly efficient O-glycan release form glycoproteins. Anal. Chem. 82, 10021-10029 (2010). 
25 Furukawa, J.- I., Shinohara, Y., Kuramoto, H., Miura, Y., Shimaoka, H., Kurogochi, M., Nakano, M. \& Nishimura, S.-I. Comprehensive approach to structural and functional glycomics based on chemoselective glycoblotting and sequential tag conversion. Anal. Chem. 80, 1094-1101 (2008).

26 Godula, K., Rabuka, D., Nam, K. T. \& Bertozzi, C. R. Synthesis and microcontact printing of dual end-functionalized mucin-like glycopolymers for microarray applications. Angew. Chem. Int. Ed. 48, 4973-4976 (2009).

27 Narain, R. \& Armes, S. P. Synthesis and aqueous solution properties of novel sugar methacrylate-based homopolymers and block copolymers. Biomacromolecules 4 , 1746-1758 (2003)

28 Bernard, J., Hao, X., Davis, T. P., Barner-Kowollik, C. \& Stenzel, M. Synthesis of various glycopolymer architecture via RAFT polymerization:from block copolymers to stars. Biomacromolecules 7, 232-238 (2006).

29 Götz, H., Harth, E., Schiller, S. M., Frank, C. W., Knoll, W. \& Hawker, C. J. Synthesis of lipo-glycopolymer amphiphilies by mediated livig free-radical polymerization. J. Polym. Sci. Part A: Polym. Chem. 40, 3379-3391 (2002).

30 Mammen, M., Choi, S. - K. \& Whitesides, G. M. Polyvalent interactions in biological systems: implications for design and use of multivalent ligands and inhibitors. Angew. Chem. Int. Ed. 37, 2754-2794 (1998)

31 Choi, S.- K. Synthetic Multivalent Molecules: Concepts and Biomedical Applications (John Wiley \&Sons, Inc., New Jersey, 2004).

32 Dam, T. K., Roy, R., Das, S. K., Oscarson, S. \& Brewer, C. F. Binding of multivalent cabohydrates to concanvalin $A$ and Dioclea grandiflora lectin: thermodynamic analysis of the 'multivalency effect'. J. Biol. Chem. 275, 14223-14230 (2000).

33 Sacchettini, J. C., Baum, L. G. \& Brewer, C. F. Multivalen protein-carbohydrate interactions. A new paradigm for supermolecular assembly and signal transduction. Biochemistry 40, 3009-3015 (2001).

34 Lundquist, J. J. \& Toone, E. J. The cluster glycoside effect. Chem. Rev. 102, 555-578 (2002)

35 Arimoto, H., Nishimura, K., Kinumi, T., Hayakawa, I. \& Uemura, D. Multi-valent polymer of vancomycin: enhanced antibacterial activity against VRE. Chem. Commun. 1361-1362 (1999).

36 Gargano, J. M., Ngo, T., Kim, J. Y., Acheson, D. W. K. \& Lees, W. J. Multivalent inhibition of AB5 toxins. J. Am. Chem. Soc. 123, 12909-12910 (2001).

37 Lundquist, J. J., Debenham, S. D. \& Toone, E. J. Multivalency effects in protein-carbohydrate interaction: the binding of the Shiga-like toxin 1 binding subunit to multivalent C-linked glycopeptides. J. Org. Chem. 65, 8245-8250 (2000).

38 Ling, $\mathrm{H}$., Boodhoo, A., Hazes, B., Cumming, M. D., Armstrong, G. D., Brunton, J. L. \& Read, R. J. Structure of the Shiga-like toxinl B-pentamer complexed with analogue of its receptor Gb3. Biochemistry 27, 1777-1788 (1998)

39 Chien, Y. Y., Jan, M. D., Adak, A. K., Tzeng, H. C., Lin, Y. P., Chen, Y. J., Wang, K. T., Chen, C. T., Chen, C. C. \& Lin, C. C. Globotriose-functionalized gold nanoparticles as multivalent probes for Shiga-like toxin. Chembiochem. 9, 1100-1109 (2008)

40 Hlavacek, W. S., Posner, R. G. \& Perelson, A. S. Steric effects on multivalent ligandreceptor binding: exclusion of ligand sites by bound cell surface receptors. Biophys. J. 76, 3031-3043 (1999).

41 Furuike, T., Nishi, N., Tokura, S. \& Nishimura, S.- I. Synthetic glycoconjugates. 6. preparation and biochemical evaluation of novel cluster-type glycopolymers containing Gal $\beta(1 \rightarrow 4)$ GlcNAc ( $N$-acetyllactosamine) residue. Macromolecules 28, 7241-7247 (1995)

42 Miura, Y., Koketsu, D. \& Kobayashi, K. Synthesis and properties of a well-defined glycopolymer via living radical polymerization. Polym. Adv. Tech. 18, 647-651 (2007).

43 Hasegawa, T., Kondoh, S., Matsuura, K. \& Kobayashi, K. Rigid helical poly(glycosyl phenyl isocyanide)s: synthesis, conformation analysis, and recognition by lectins. Macromolecules 32, 6595-6603 (1995).

44 Ooya, T., Eguchi, M. \& Yui, N. Supramolecular design for multivalent interaction: maltose mobility along polyrotaxane enhanced binding with Concanavalin A. J. Am. Chem. Soc. 125, 13016-13017 (2003).

45 Kobayashi, K., Sumitomo, H. \& Ina, Y. Synthesis and functions of polystyrene derivatives having pendant oligosaccharides. Polym. J. 17, 567-575 (1985).

46 Kobayashi, K., Akaike, T., Kobayashi, K. \& Sumitomo, H. Enhanced adhesion and survival efficiency of liver cells in culture dishes coated with a lactose-carrying styrene homopolymer. Mokromol. Chem. Rapid. Commun. 7, 645-650 (1986)

47 Sparks, M. A., Williams, K. W. \& Whitesides, G. M. Neuraminidase-resistant hemagglutination inhibitors: acrylamide copolymers containing a C-glycoside of $\mathrm{N}$-acetylneuraminic acid. J. Med. Chem. 36, 778-783 (1993).

48 Li, J., Zacharek, S., Chen, X., Wang, J., Zhang, W., Janczuk, A. \& Wang, P. G. Bacteria targeted by human natural antibodies using $\alpha$-Gal conjugated receptor-specific glycopolymers. Bioorg. Med. Chem. 7, 1549-1558 (1999).

49 Tanaka, H., Nishida, Y., Furuta, Y. \& Kobayashi, K. A convenient synthetic pathway for multivalent assembly of aminoglycoside antibiotics starting from akikacin. Bioorg. Med. Chem. Lett. 12, 1723-1726 (2002).

50 Tsuchida, A., Matsuura, K. \& Kobayashi, K. A quartz-crystal microbalance study of adsorption behavior of artificial glycoconjugate polymers with different saccharide chain lengths and with different backbone structure. Macromol. Chem. Phys. 201, 2245-2250 (2000).

51 Wataoka, I., Urakawa, H., Kobayashi, K., Ohono, K., Fukuda, T., Akaike, T. \& Kajiwara, K. Molecular specification of homopolymer of vinylbenzyl-lactose-amide in aqueous solution. Polymer J. 31, 590-594 (1999).

52 Wataoka, I., Urakawa, H., Kobayashi, K., Akaike, M., Schimidt, M. \& Kajikawa, K. Rigid helical poly(glycosyl phenyl isocyanide)s: synthesis, conformational analysis, and recognition by lectins. Macromolecules 32, 6595-6603 (1999).
53 Fukuda, T., Inoue, Y., Koga, T., Matsuoka, M. \& Miura, Y. Encapsulation of polythiophene by glycopolymer for water-soluble nanowire. Chem. Lett. 40, 864-866 (2011)

54 Miura, Y. Sato, H., Ikeda, T., Sugimura, H., Takai, O. \& Kobayashi, K. Microatterned carbohydrate display by self-assembly of glycoconjugate polymers on hydrophobic templates on silicon. Biomacromolecules 5, 1708-1713 (2004).

55 Sato, H., Miura, Y., Saito, N., Kobayashi, K. \& Takai, O. A micropatterned multifunctional carbohydrate display by an orthogonal self-assembling strategy. Biomacromolecules 8, 753-756 (2007).

56 Pearson, S., Chen, G. \& Stenzel, M. H. in Engineered Carbohydrate-Based Materials for Biomedical Applications: Polymers, Surfaces, Dendrimers, Nanoparticles, and Hydrogels (ed. Narain, R.) 1-118 (Wiley, New York, 2011).

57 Slavin, S., Burns, J., Haddleton, D. M. \& Becer, C. R. Synthesis of Glycopolymers via click reactions. Eur. Polym. J. 47, 435-446 (2011).

58 Spain, S. G. \& Cameron, N. R. A spoonful of sugar: the application of glycopolymers in therapeutics. Polym. Chem. 2, 60-68 (2011).

59 Spain, S. G., Gibson, M. I. \& Cameron, N. R. Recent advances in the synthesis of well-defined glycopolymers. J. Polym. Sci. Part A: Polym. Chem. 45, 2059-2072 (2007)

60 Ting, S. S. R., Chen, G. \& Stenzel, M. H. Synthesis of glycopolymers and their multivalent recognitions with lectins. Polym. Chem. 1, 1392-1412 (2010).

61 Hawker, C. J., Bosman, A. W. \& Harth, E. New polymer synthesis by Nitroxide mediated living radical polymerizations. Chem. Rev. 101, 3661-3688 (2001)

62 Kamigaito, M., Ando, T. \& Sawamoto, M. Metal-catalyzed living radical polymerization. Chem. Rev. 101, 3689-3746 (2001).

63 Matyjaszewski, K. \& Xia, J. Atom transfer radical polymerization. Chem. Rev. 101, 2921-2990 (2001)

64 Chiefari, J., Chong, Y. K., Ercole, F., Krstina, J., Jeffery, J., Le, T. P. T., Mayadunne, R. T., Meijs, G. F., Moad, C. L., Graeme, M., Rizzardo, E. \& Thang, S. H. Living freeradical polymerization by reversible addition-fragmentation chain transfer: the RAFT process. Macromolecules 31, 5559-5562 (1998).

65 Ohno, K., Tsujii, Y., Miyamoto, T., Fukuda, T., Goto, M., Kobayashi, K. \& Akaike, T. Synthesis of a well-defined glycopolymer by nitroxide-controlled free radical polymerization. Macromolecules 31, 1064-1069 (1998)

66 Ohno, K., Fukuda, T. \& Kitano, H. Free radical polymerization of a sugar residuecarrying styryl monomer with a lipophilic alkoxyamine initiator: synthesis of a welldefined novel glycolipid. Macromol. Chem. Phys. 199, 2193-2197 (1998).

67 Wataoka, I., Urakawa, H., Kobayashi, K., Akaike, T., Schmidt, M. \& Kajiwara, K. Structural. characterization of glycoconjugate polystyrene in aqueous solution. Macromolecules 32, 1816-1821 (1999).

68 Chen, Y. \& Wulff, G. Amphiphilic block copolymers with pendent sugar as hydrophilic segments and their surface properties. Macromol. Chem. Phys. 202, 3273-3278 (2001).

69 Chen, Y. \& Wulff, G. Synthesis of poly(styryl sugar)s by TEMPO mediated free radical polymerization. Macromol. Chem. Phys. 202, 3426-3431 (2001).

70 Narumi, A., Matsuda, T., Kaga, H., Satoh, T. \& Kakuchi, T. Synthesis of amphiphilic triblock copolymer of polystyrene and poly(4-vinylbenzyl glucoside) via TEMPOmediated living radical polymerization. Polymer 43, 4835-4840 (2002).

71 Narumi, A., Satoh, T., Kaga, H. \& Kakuchi, T. Glycoconjugate polymer.3. Synthesis and amphiphilic property of core-glycoconjugated star-shaped polystyrene. Macromolecules 35, 699-705 (2002)

72 Ting, S. R. S., Min, E. H., Escalé, P., Save, M., Billon, L. \& Stenzel, M. H. Lectin recognizable biomaterials synthesized via nitroxide-mediated polymerization of a methacryloyl galactose monomer. Macromolecules 42, 9422-9434 (2009).

73 Ohno, K., Goto, A., Fukuda, T., Xia, J. \& Matyjaszewski, K. Kinetic study on the activation process in an atom transfer radical polymerization. Macromolecules 31, 2699-2701 (1998).

74 Narain, R. \& Armes, S. P. Synthesis of low polydispersity, controlled chemistry. Chem. Commun. 23, 2776-2777 (2002)

75 Li, Z - C. Chen, G. Q \& Li, F- M. Synthesis of amphiphilic block copolymers with well-defined glycopolymer segment by atom-transfer radical polymerization. Macromol. Rapid Commun. 21, 375-380 (2000).

76 Meng, J.- Q., Du, F.- S., Liu, Y.- S. \& Li, Z.- C. Atom transfer radical polymerization of 6-methacryloyl-1,2,3,4-di-O-isopropylidene D-galactopyranose in solution. J. Polym. Sci. Part A: Polym. Chem. 43, 752-762 (2005).

77 Dai, X. H. \& Dong, C. M. Synthesis, self-assembly and recognition properties of biomimetic star-shaped poly(e-caprolactone)-b-glycopolymer block copolymers. J. Polym. Sci. Part A: Polym. Chem. 46, 817-829 (2008).

78 Qu, S., Huang, H., Dai, X. H., Zhou, W. \& Dong, C. M. Star-shaped polypeptide/ glycopolymer biohybrids: synthesis, self-assembly, biomolecular recognition, and controlled drug release behavior. J. Polym. Sci. Part A: Polym. Chem. 47, 2009-2023 (2009)

79 Muthukrishnan, S., Mori, H. \& Muller, A. H. E. Synthesis and characterization of methacrylate-type hyperbranched glycopolymers via self-condensing atom transfer radical copolymerization. Macromolecules 38, 3108-3119 (2005).

80 Muthukrishnan, S., Erhard, D. P., Mori, H. \& Muller, A. H. E. Synthesis and characterization of surface-grafted hyperbranched glycomethacrylates. Macromolecules 39, 2743-2750 (2006).

81 Ejaz, M., Ohno, K., Tsujii, Y. \& Fukuda, T. Controlled grafting of a well-defined glycopolymer on a solid surface by surface-initiated atom transfer radical polymerization. Macromolecules 33, 2870-2874 (2000).

82 Lowe, A. B., Sumerlin, B. S. \& McCormick, C. L. The direct polymerization of 2 methacryloxyethyl glucoside via aqueous reversible addition-fragmentation chain transfer (RAFT) polymerization. Polymer 44, 6761-6765 (2003). 
83 Wang, J., Zhu, X., Cheng, Z., Zhang, Z. \& Zhu, J. Preparation, characterization and chiral recognition of optically active polymers containing pendant chiral units via reversible addition-fragmentation chain transfer polymerization. J. Polym. Sci. Part A: Polym. Chem. 45, 3788-3797 (2007).

84 Yiao, N.- I., Li, A.- L., Liang, H. \& Lu, J. A well-defined novel aldehyde-functionalized glycopolymer: synthesis, micelle formation, and its protein immobilization. Macromolecules 41, 2374-2380 (2008).

85 Pasparakis, G. \& Alexander, C. Sweet talking hydrophilic block copolymer vesicles. Angew. Chem. Int. Ed. 47, 4847-4850 (2008).

86 Deng, Z., Li, S., Jiang, X. \& Narain, R. Well-defined galactose-containing multifunctional copolymers and glyconanoparticles for biomolecular recognition processes. Macromolecules 42, 6393-6405 (2009).

87 Albertin, L., Stenzel, M. H., Barner-Kowollik, C., Foster, L. J. R. \& Davis, T. P. Welldefined diblock glycopolymers from RAFT polymerization in homogeneous aqueous medium. Macromolecules 38, 9075-9084 (2005).

88 Albertin, L., Stenzel, M., Barner-Kowollik, C., Foster, L. J. R. \& Davis, T. P. Well-defined Glycopolymers from RAFT polymerization in water. Polymer 47, 1011-1019 (2006)

89 Albertin, L., Stenzel, M., Barner-Kowolik, C., Foster, L. J. R. \& Davis, T. P. Well-defined glycopolymers from RAFT polymerization: Poly(methyl 6-methacryloyl- $\alpha$-D-glucoside) and its block copolymer with 2-hydroxyethyl methacrylate. Macromolecules 37, 7530-7537 (2004)

90 Albertin, L. \& Cameron, N. R. RAFT polymerization of methyl 6-0-methacryloyl-R-Dglucoside in homogeneous aqueous medium. A detailed kinetic study at the low molecular weight limit of the process. Macromolecules 40, 6082-6093 (2007).

91 Zhang, L., Bernard, J., Davis, T. P., Barner-Kowollik, C. \& Stenzel, M. H. Acid-degradable core-crosslinked micelles prepared from thermosensitive glycopolymers synthesized via RAFT polymerizationa. Macromol. Rapid Commun. 29, 123-129 (2008).

92 Ting, S. R. S., Gregory, A. M. \& Stenzel, M. H. Polygalactose containing nanocages: the RAFT process for the synthesis of hollow sugar balls. Biomacromolecules 10, 342-352 (2009).

93 Albertin, L., Kohlert, C., Stenzel, M., Foster, L. J. R. \& Davis, T. P. Chemoenzymatic synthesis of narrow-polydispersity glycopolymers: poly(6-O-vinyladipoyl-D-glucopyranose). Biomacromolecules 5, 255-260 (2004).

94 Bernard, J., Favier, A., Zhang, L., Nilasaroya, A., Davis, T. P., Barner-Kowollik, C. \& Stenzel, M. H. Poly(vinyl ester) star polymers via xanthate-mediated living radical polymerization: from poly(vinyl alcohol) to glycopolymer stars. Macromolecules $\mathbf{3 8}$, 5475-5484 (2005).

95 Roth, P. J., Boyer, C., Lowe, A. B. \& Davis, T. P. RAFT Polymerization and thiol chemistry a complementary paring for implementing modern macromolcecular design. Macromol. Rapid Commun. 32, 1123-1143 (2011).

96 Morokoshi, S., Ohhori, K., Mizukami, K. \& Kitano, H. Sensing capabilities of colloidal gold modified with a self-assembled monolayer of a glucose-carrying polymer chain on a glass substrate. Langmuir 20, 8897-8902 (2004)

97 Boyer, C. \& Davis, T. P. One-pot synthesis and biofunctionalization of glycopolymers via RAFT polymerization and thiol-ene reactions. Chem. Commun. 6029-6031 (2009).

98 Lowe, A. B. Thiol-ene 'click' reactions and recent applications in polymer and materials synthesis. Polym. Chem. 1, 17-36 (2010)

99 Kamitani, R., Niikura, K., Onodera, T., Iwasaki, N., Shimaoka, H. \& ljiro, K. Patterned immobilization of unprotected carbohydrates on an aminooxy polymer-grafted solid surface. Bull Chem Soc. Jpn. 80, 1808-1813 (2007).

100 You, L. \& Schlad, H. An easy way to sugar-containing polymer vesicles or glycosomes. J. Am. Chem. Soc. 128, 13336-13337 (2006).

101 Strong, L. E. \& Kiessling, L. L. A general synthetic route to defined, biologically active multivalent arrays. J. Am. Chem. Soc. 121, 6193-6196 (1999).

102 Vougioukalakis, G. C. \& Grubbs, R. H. Ruthenium-based heterocyclic carbine-coordinated olefin metathesis catalysts. Chem. Rev. 110, 1746-1787 (2010).

103 Cairo, C. W., Gestwicki, J. E., Kanai, M. \& Kiessling, L. L. Control of multivalent interactions by binding epitope density. J. Am. Chem. Soc. 124, 1615-1619 (2002).

104 Gestsicki, J. E. \& Kiessling, L. L. Inter-receptor communication through arrays of bacterial chemoreceptors. Nature 415, 81-84 (2002).

105 Kanai, M., Mortell, K. H. \& Kiessling, L. L. Varying the size of multivalent ligands: the dependence of concanavalin A binding on neoglycopolymer length. J. Am. Chem. Soc. 119, 9931-9932 (1997)

106 Ladmiral, V., Mantovani, G., Clarkson, G. J., Cauet, S., Irwin, J. L. \& Haddleton, D. M. Synthesis of neoglycopolymers by a combination of 'click chemistry' and living radical polymerization. J. Am. Chem. Soc. 128, 4823-4830 (2006).

107 Gestwicki, J. E., Cairo, C. W., Strong, L. E., Oetjen, K. A. \& Kiessling, L. L. Influencing receptor-ligand binding mechanisms with multivalent ligand architecture. J. Am. Chem. Soc. 124, 14922-14933 (2002).

108 Gordon, E. J., Gestwicki, J. E., Strong, L. E. \& Kiessling, L. L. Synthesis of end-labeled multivalent ligands for exploring cell-surface-receptor-ligand interactions. Chem. Biol. 7, 9-16 (2000)

109 Miura, Y. \& Mizuno, H. Interaction analyses of amyloid $\beta$ peptide(1-40) with glycosaminoglycan model polymers. Bull Chem. Soc. Jpn. 83, 1004-1009 (2010).

110 Miura, Y., Yasuda, K., Yamamoto, K., Koike, M., Nishida, Y. \& Kobayashi, K. Inhibition of Alzheimer amyloid aggregation with sulfated glycopolymers. Biomacromolecules $\mathbf{8}$, 2129-2134 (2007)
111 Becer, C. R., Gibson, M. I., Geng, J., Ilyas, R., Wallis, R., Mitchell, D. A. \& Haddleton, D. M. High-affinity glycopolymer binding to human DC-SIGN and disruption of DC-SIGN interactions with HIV envelope glycoprotein. J. Am. Chem. Soc. 132, 15130-15132 (2010).

112 Yang, Q., Strathmann, M., Rumpf, A., Schaule, G. \& Ulbricht, M. Grafted glycopolymer-based receptor mimics on polymer support for selective adhesion of bacteria. ACS Appl. Mater. Interfaces 2, 3555-3562 (2010).

113 Pearson, S., Allen, N. \& Stenzel, M. H. Core-shell particles with glycopolymer shell and polynucleoside core via RAFT: from micelles to rods. J. Polym. Sci. Part A, Polym. Chem. 47, 1708-1728 (2009).

114 Narain, R., Housni, A. G. \& Lane, L. Modification of carboxyl-functionalized singlewalled carbon nanotubes with biocompatible, water-soluble phosphorylcholine and sugar-based polymers: bioinspired nanorods. J. Polym. Sci. Part A: Polym. Chem. 44, 6558-6568 (2006).

115 Gao, C., Muthukrishnan, S., Li, W., Yuan, J. \& Muller, A. E. Linear and hyperbranched glycopolymer-functionalized carbon nanotubes: synthesis, kinetics and characterization. Macromolecules 40, 1803-1815 (2007).

116 Jiang, X., Housni, A., Gody, G., Boullanger, P., Charreyre, M.- T., Delair, T. \& Narain, R. Synthesis of biotinylated $\alpha$-D-mannoside or $N$-Acetyl $\beta$-D-glucosaminoside decorated gold nanoparticles: Study of their biomolecular recognition with Con A and WGA lectins. Bioconjug. Chem. 21, 521-530 (2010).

117 Ladmiral, V., Mantovani, G., Clarkson, G. J., Cuet, S. \& Irwin, J. L. Synthesis of neoglycopolymers by a combination of 'click chemistry' and living radical polymerization. J. Am. Chem. Soc. 128, 4823-4830 (2006).

118 Sun, X.- L., Cui, W., Haller, C. \& Chaikof, E. L. Site-specific multivalent carbohydrate labeling of quantum dots and magnetic beads. ChemBioChem. 5, 1593-1596 (2004).

119 Dai, X.- H., Dong, C.- M. \& Yan, D. Supramolecular and biomimetic polypseudorotaxane/glycopolymer biohybrids: synthesis, glucose-surfaced nanoparticles, and recognition with lectin. J. Phys. Chem. B 112, 3644-3652 (2008).

120 Dai, X.- H., Zhang, H.- D. \& Dong, C. M. Fabrication, biomolecular binding, in vitro drug release behavior of sugar-installed nanoparticles from star poly( $\varepsilon$-caprolactone)/ glycopolymer biohybrid with a dendrimer core. Polymer 50, 4626-4634 (2009).

121 Toyoshima, M. \& Miura, Y. Preparation of glycopolymer-substituted gold nanoparticles and their molecular recognition. J. Polym. Sci. Part A, Polym. Chem. 47, 1412-1421 (2009).

122 Toyoshima, M., Oura, T., Fukuda, T., Matsumoto, E. \& Miura, Y. Biological specific recognition of glycopolymer-modified interfaces by RAFT living radical polymerization. Polym. J. 42, 172-178 (2010)

123 Ishii, J., Toyoshima, M., Chikae, M., Takamura, Y. \& Miura, Y. Preparation of glycopolymer-modified gold nanoparticles and a new approach for a lateral flow assay. Bull Chem. Soc. Jpn. 84, 466-470 (2011).

124 Ishii, J., Chikae, M., Toyoshima, M., Ukita, Y., Miura, Y. \& Takamura, Y. Electrochemical assay for saccharide-protein interactions using glycopolymer-modified gold nanoparticles. Electrochem. Commun. 13, 830-833 (2011).

125 Jiang, X., Ahmed, M. Deng, Z. \& Narain, R. Biotinylated glyco-functionalized quantum dots: synthesis, characterization, and cytotoxicity studies. Bioconjug. Chem. 20, 994-1001 (2009).

126 Ahmed, M., Deng, Z. \& Narain, R. Study of transfection efficiencies of cationic glyconanoparticles of different sizes in human cell line. ACS Appl. Mater. Interfaces 1, 1980-1987 (2009)

127 Broyer, R. M., Quaker, G. M. \& Maynard, H. D. Designed aminoacide ATRP initiators for the synthesis of biohybrid materials. J. Am. Chem. Soc. 130, 1041-1047 (2008).

128 Vázquez-Dorbatt, V., Tolstyka, Z. P., Chang, C.- W. \& Maynard, H. D. Synthesis of a pyridyl disulfide end-functionalized glycopolymer for conjugation to biomolecules and pattering on gold surfaces. Biomacromolecules 10, 2207-2212 (2009).

129 Gupta, S. S., Raja, K. S., Kaltgrad, E., Strable, E. \& Finn, M. G. Virus-glycopolymer conjugates by copper(I) catalysis of atom transfer radical polymerization and azidealkyne cycloaddition. Chem. Commun. 4315-4317 (2005).

130 Thurecht, K. J., Blakey, I., Peng, H., Squires, O., Hsu, S., Alexander, C. \& Whittaker, A. K. Functional hyperbranched polymers: toward targeted in vivo $19 \mathrm{~F}$ magnetic resonance imaging using designed macromolecuels. J. Am. Chem. Soc. 132, 5336-5337 (2010)

131 Chen, X., Chong, U. C., Czlapinski, J. L., Lee, G. S., Rabuka, D., Zettl, A. \& Bertozzi, C. R. Interfacing carbon nanotubes with living cells. J. Am. Chem. Soc. $128,6292-6293$ (2006)

132 Tsujii, Y., Ohno, K., Yamamoto, S., Goto, A. \& Fukuda, T. Structure and properties of high-density polymer brushes prepared by surface-initiated living radical polymerization. Adv. Polym. Sci. 197, 1-45 (2006).

$133 \mathrm{Yu}$, K. \& Kizhakkedathu, J. N. Synthesis of functional polymer brushes containing carbohydrate residues in the pyranose form and their specific and nonspecific interactions with proteins. Biomacromolecules 11, 3073-3085 (2010).

134 Raynor, J. E., Petrie, T. A., Fears, K. P., Latour, R. A., Garcia, A. J. \& Collard, D. M. Saccharide polymer brushes to control protein and cell adhesion to titanium. Biomacromolecules 10, 748-755 (2009).

135 Kitano, H., Takahashi, Y., Mizukami, K. \& Matsuura, K. Kinetic study on the binding of lectin to mannose residues in a polymer brush. Coll. Surf. B 70, 91-97 (2009).

136 Mateescu, A., Ye, J., Narain, R. \& Vamvakaki, M. Synthesis and characterization of novel glycosurfaces by ATRP. Soft Matter 5, 1621-1629 (2009). 


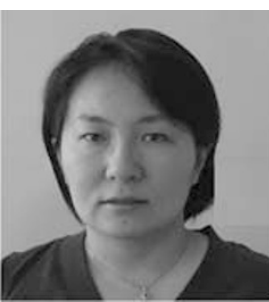

Yoshiko Miura is currently Professor of Kyusyu University. Yoshiko Miura received her B Eng. Degree in 1995, M Eng. Degree in 1997 from the Kyoto University under the supervision of Professor Yukio Imanishi. She received Dr Eng. Degree in 2000 from the Kyoto University under the supervision of Professor Shiro Koabayashi. She spent her postdoctoral period from 2000 to 2001 at the University of Pennsylvania in Professor Virgil Percec's group. In 2001, she joined the Department of Molecular Design and Engineering, Nagoya University as Assistant Professor, and started the research of glycomaterials with Professor Kazukiyo Kobayashi. In 2005, she was appointed Associate Professor at the Schools of Materials Science in Japan Advanced Institute of Science and Technology. In 2010, she was appointed Professor at the Department of Chemical Engineering, in Kyushu Univerisity. Her research interests are biomaterial fabrication with glycopolymers and glyco-nanoparticles. 